\title{
Influence of Surcharge Loading, Retained Soil and Restrained Soil on Design of Diaphragm Wall
}

\author{
$\mathrm{Nu} \mathrm{Nu} \mathrm{Win}^{1}$, Nyan Myint Kyaw ${ }^{2}$, Khin Than $\mathrm{Yu}^{3}$ \\ ${ }^{1,2,3}$ Faculty of Civil Engineering, Yangon Technological University, Myanmar \\ *Corresponding author: ${ }^{1}$ dawnunuwin.civil@gmail.com, ${ }^{2}$ nmkyaw@gmail.com, ${ }^{3}$ khinthanyu@gmail.com ${ }^{3}$
}

\begin{abstract}
Many different types of embedded retaining wall are constructed due to the increasing demands. In Yangon, Myanmar is encountered deep excavation problem. Many buildings are damaged due to excavation of adjacent building. Therefore, embedded retaining wall as excavation support system is necessary to be sustainable buildings. There are important that influence of surcharge loading, retained soil and restrained soil on design of embedded retaining wall. In this paper, diaphragm Wall is emphasized and solved using soil structure interaction analysis. Behaviour of diaphragm Wall wall is based on various factors. Consider with natural and increasing of shear strength parameter of retained and restrained soils to get the level of the dredge line is stiff soil and various distances from wall to surcharge. Sites are located in urban setting, there are near building and separately from main structure. This project involves the construction of $5 \mathbf{m}$ depth retaining wall. In case study (A) retained soils is soft, medium (low) clay, restrained soil is mostly cohesive soil. There are medium (low), stiff, medium, hard soil layers. In case studies (B to $\mathbf{H})$ are increasing shear strength parameter of retained soil and restrained soil. All cases are considered with various distances from wall to surcharge. According to the soil conditions and distance from wall to surcharge, Wall depth, horizontal and vertical movement of ground and wall deflection are described. When retained and restrained soil reach stiff condition, then ground movement and wall deflection reach acceptable limit and wall depth become more safe and economical condition.
\end{abstract}

Keywords - shear strength parameter, wall depth, deep excavation, horizontal and vertical movement, wall deflection, soil conditions.

\section{INTRODUCTION}

$\mathrm{T}$

here are different types of embedded retaining wall;

they are sheet pile wall, contiguous bored pile wall, secant bored pile wall and diaphragm wall, king post wall. It is possible to make economies in embedded retaining walls by selecting an appropriate wall type and support system for the future possibility construction sequence and long-term use.

A. Objective of the this paper is

1. To find behavior of diaphragm wall based on various factors

2. To find influence of surcharge loading , retained soil and restrained soil on design of diaphragm walls.

B. Scope of the this paper is

1. Sites are located in urban setting, there are near building and separately from main structure.

2. This project involves the construction of $5 \mathrm{~m}$ depth retaining wall.

3. Selections of design parameters are considered according to the soil profile and laboratory results.

4. Constant surcharge load is 0.5 ton $/ \mathrm{ft}^{2}$ and
5. Level ground surface retained soils are considered.

C. Methodology-

1. Establishing of limit states

2. Reviewing ground and ground water conditions

3. Selection of wall type

4. Finding of loads

5. Determination of wall depth for overall lateral stability using ultimate limit state

6. Prediction of wall deflections and ground surface movements using serviceability limit states.

\section{Outline of the paper}

This paper is composed five chapters.

1. Chapter one introduces the general information together with objective, scope of the study, methodology.

2. Chapter two states methodology of the design stages of embedded retaining walls.

3. Chapter three describes results and discussion about design of diaphragm wall using soil structure interaction analysis based on various soil conditions.

4. Chapter four contains conclusion.

5. Chapter five describes acknowledgements

6. Chapter six comprises References. 


\section{METHODOLOGY}

\section{A.Establishing of limit states}

1. Ultimate limit states -with collapse or with other similar forms of structural failure. To cause safety of people and the safety of the structure.

2. Serviceability limit states correspond to specific service performance requirements. To use predefined limits on the wall deflection

B. Reviewing ground and ground water conditions
3. The purpose of design calculation- is to ensure: Satisfactory safety and overall stability of the wall at the ultimate limit state.

Acceptable deformation and performance at the serviceability limit state.

The purpose of the factors is to allow for uncertainty in material properties.

Table 1. Subsoil Stratification

\begin{tabular}{|c|c|c|c|c|c|c|}
\hline $\begin{array}{c}\text { BH } \\
\text { No. }\end{array}$ & Layer & Depth(m) & Subsoil Type & $\begin{array}{c}\text { SPT } \\
\text { Range }\end{array}$ & $\begin{array}{c}\text { Average SPT } \\
\text { Value }\end{array}$ & Description \\
\hline \multirow{7}{*}{ BH-01 } & I & $0-1.5$ & Top soil & - & - & Soft \\
\cline { 2 - 7 } & II & $1.5-3.00$ & $\mathrm{CL}$ & $0-4$ & 2 & medium \\
\cline { 2 - 7 } & III & $3.0-15.0$ & $\mathrm{CH}$ & $2-5$ & 16 & Stiff \\
\cline { 2 - 7 } & $\mathrm{IV}$ & $15.0-19.5$ & $\mathrm{CL}$ & $13-20$ & 8 & medium \\
\cline { 2 - 7 } & $\mathrm{V}$ & $19.5-25.5$ & $\mathrm{CH}, \mathrm{CL}$ & $5-12$ & Hard \\
\cline { 2 - 7 } & $\mathrm{VI}$ & $25.5-34.5$ & $\mathrm{CH}$ & $15-75$ & 40 & V Stiff \\
\cline { 2 - 7 } & $\mathrm{VII}$ & $34.5-39.0$ & $\mathrm{CL}, \mathrm{CH}$ & $14-45$ & 24 & V Dense \\
\hline
\end{tabular}

Table 2. Ground water level

\begin{tabular}{|c|c|c|c|}
\hline BH No. & $\begin{array}{c}\text { Below Ground Water } \\
\text { Table }(\mathrm{m})\end{array}$ & $\begin{array}{c}\text { Termination } \\
\text { Depth(m) }\end{array}$ & Remark \\
\hline BH-01 & 2.00 & 41 & Min: 1.5 m, max: 3.5 depth BGL \\
\hline
\end{tabular}

\section{Selection of wall type}

Case study (A)

1. Bo Ba Htoo Project, North Dagon Town Ship , Yangon

2. Retained soils is soft, medium clay,

3. Restrained soil is mostly cohesive soil. There are medium (low), stiff, medium, hard soil layers.

4. Water level is average $2 \mathrm{~m}$ below the ground surface.

5. Suitable for Diaphragm Wall. 

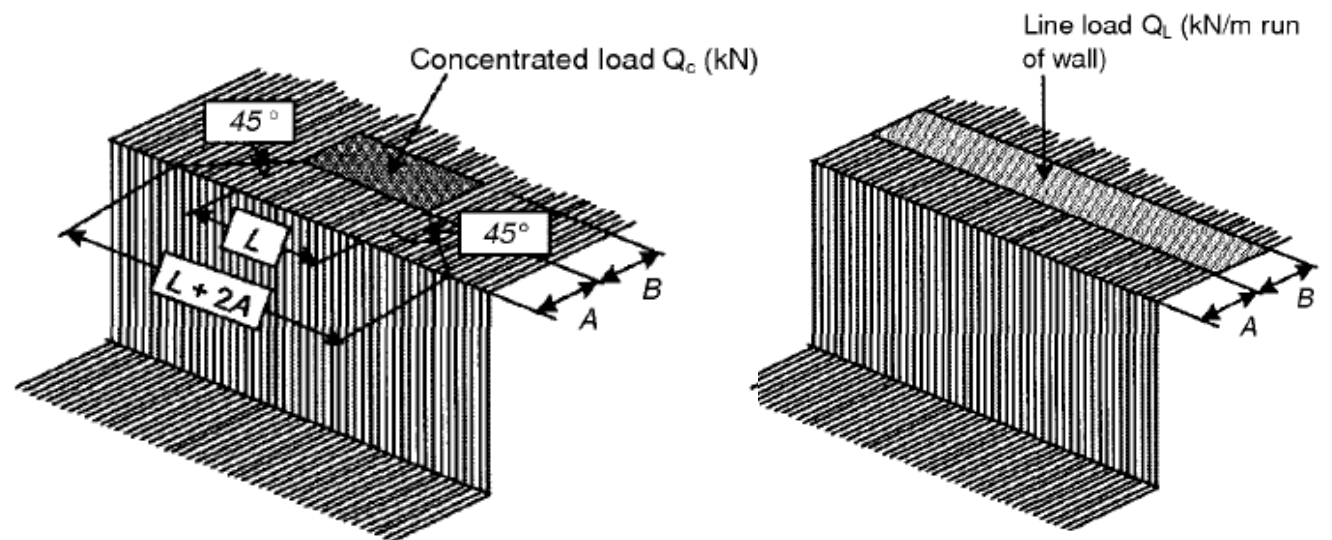

Figure 1.Concentrated and line load surcharges

with $\mathrm{FS}=1$ for shear strength parameter.

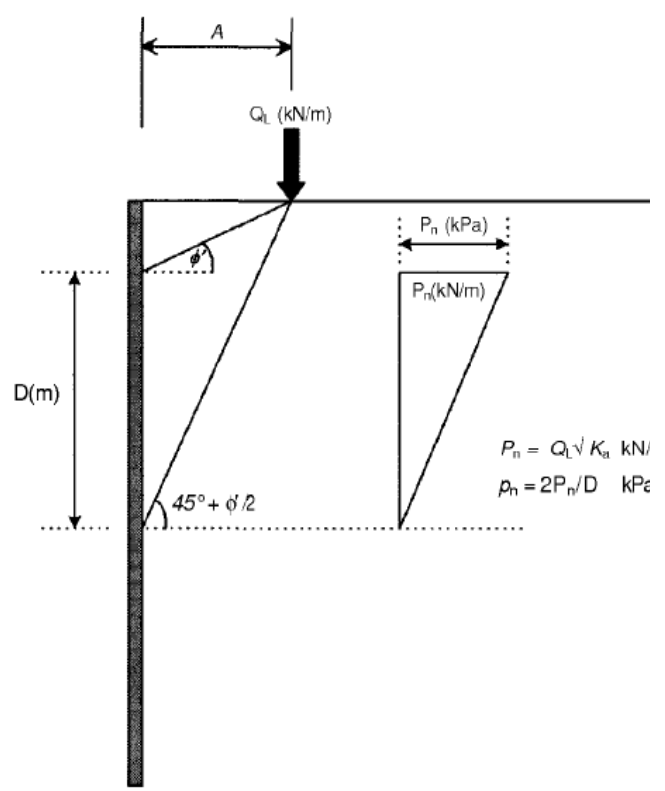

Figure 2. Pressure Diagram Line Load

E. Determination of wall depth for overall lateral stability

1. In case study (A) retained soils is soft, medium (low) clay, restrained soil medium (low), stiff, medium, hard soil layers.

2. In case studies (B to $\mathrm{H}$ ) with increasing shear strength parameter of retained and restrained soils to get the level of the dredge line is stiff soil.

In this study, soil structure interaction analysis is used for wall depth with overall lateral stability with $\mathrm{FS}=1.4$ for $\mathrm{c}$ and $\mathrm{FS}=1.25$ for $\phi . \mathrm{E}_{\mathrm{ULS}}=1 / 2 \mathrm{E}_{\mathrm{SLS}}$.

F. Prediction of wall deflections and ground surface movements using serviceability limit states

\section{RESULTS AND DISCUSSION}

A. Case study (A) Distance from wall to Building $=0 \mathrm{~m}$, $0.2 m, 0.4 m, 0.6 m, 0.8 m, 1 m, 1.2 m$

Surcharge loads are $13,13,13,13,13,12.5,12.5 \mathrm{kN} / \mathrm{m}^{2}$ respectively.

Table 3 shows Summaries of Ground Parameters

Figure 2 shows wall depth with distance from wall to surcharge, figure 2A is SUM Msf with distance from wall to surcharge and Figure 3 shows ground movement with distance from wall to surcharge .From the figures,

1. In ULS, $30 \mathrm{~m}$ wall depth is needed for all distances from wall to surcharge. SUM Msf 1.455 is at zero $\mathrm{m}$ distance from wall to surcharge and Maximum SUM Msf is 1.459 is at $1.2 \mathrm{~m}$ distances from wall to surcharge. Minimum SUM Msf is 1.447 at $0.4,0.6,0.8 \mathrm{~m}$ distances from wall to surcharge.

2. In SLS, $23 \mathrm{~m}$ wall depth is required for all distances from wall to surcharge. SUM Msf1.448 is at zero $\mathrm{m}$ distance from wall to surcharge and Maximum SUM Msf 1.45 at 1and $1.2 \mathrm{~m}$ distances from wall to surcharge. Minimum of SUM Msf is 1.436 at $0.6 \mathrm{~m}$ distances from wall to surcharge.

3. Horizontal ground movement is $178.79 \mathrm{~mm}$ at zero $\mathrm{m}$ distance from wall to surcharge and Minimum horizontal displacement is 174.11 $\mathrm{mm}$ at $1.2 \mathrm{~m}$ distance from wall to surcharge. Wall deflections are same to horizontal displacement. Maximum horizontal displacement is $179.53 \mathrm{~mm}$ at $0.4 \mathrm{~m}$ distance from wall to surcharge.

4. Vertical ground movement is $215.38 \mathrm{~mm}$ at zero $\mathrm{m}$ distance from wall to surcharge and Minimum vertical displacement is $214.36 \mathrm{~mm}$ at $1.0 \mathrm{~m}$ distance from wall to surcharge. Maximum vertical displacement is $215.89 \mathrm{~mm}$ at $0.6 \mathrm{~m}$ distance from wall to surcharge 
B. CASE B $1.5 \%$ Increasing shear strength parameter

1. In ULS, $23 \mathrm{~m}$ wall depth is needed for all distances from wall to surcharge. SUM Msf 1.617 is at zero $\mathrm{m}$ distance from wall to surcharge and Maximum SUM Msf is 1.621 at $1.2 \mathrm{~m}$ distances from wall to surcharge. Minimum SUM Msf is 1.6 at $0.6 \mathrm{~m}$ distances from wall to surcharge.

2. In SLS, $17 \mathrm{~m}$ wall depth is required for all distances from wall to surcharge. Horizontal ground movement is $151.9 \mathrm{~mm}$ at zero $\mathrm{m}$ distance from wall to surcharge and Minimum horizontal displacement is $138.21 \mathrm{~mm}$ at $1.2 \mathrm{~m}$ distance from wall to surcharge. Wall deflections are same to horizontal displacement. Maximum horizontal displacement is 152.63 $\mathrm{mm}$ at $0.6 \mathrm{~m}$ distance from wall to surcharge.
3. Vertical ground movement is 191.95 to 192.14 $\mathrm{mm}$ for all distances from wall to surcharge.

C. CASE C $2.0 \%$ Increasing shear strength parameter

1. In ULS, $17 \mathrm{~m}$ wall depth is needed for all distances from wall to surcharge. SUM Msf 1.52 is at zero $\mathrm{m}$ distance from wall to surcharge and Maximum SUM Msf is 1.526 at $1.2 \mathrm{~m}$ distances from wall to surcharge. Minimum SUM Msf is 1.508 at $0.6 \mathrm{~m}$ distances from wall to surcharge.

2. In SLS, $17 \mathrm{~m}$ wall depth is required for all distances from wall to surcharge. Horizontal ground movement is $131.12 \mathrm{~mm}$ at zero $\mathrm{m}$ distance from wall to surcharge and Minimum horizontal displacement is $130.63 \mathrm{~mm}$ at $1.2 \mathrm{~m}$ distance from wall to surcharge. Wall deflections are same to horizontal displacement. Maximum horizontal displacement is $131.7 \mathrm{~mm}$ at $0.6 \mathrm{~m}$ distance from wall to surcharge.

3. Vertical ground movement is 159.23 to 159.37 $\mathrm{mm}$ for all distances from wall to surcharge.

Table 3. Summaries of Ground Parameters for Case Study A

\begin{tabular}{ccccccccc}
\multicolumn{7}{c}{ Table 3. Summaries of Ground Parameters for Case Study A } \\
\hline \multirow{2}{*}{ Particu } & I & II & III & IV & V & VI & VII & Unit \\
lar & CL & CH & CL & CH,CL & CH & CL,CH & SM & \\
& $(1.5-$ & $(3.0-$ & $(15.0-20)$ & $(20-$ & $(26.0-$ & $(36.0-$ & $(39.0-$ & \\
& $3.0)$ & $15.0)$ & $\mathrm{m}$ & $26.0)$ & $35.0)$ & $39.0)$ & $41.0)$ & \\
& $\mathrm{m}$ & $\mathrm{m}$ & & $\mathrm{m}$ & $\mathrm{m}$ & $\mathrm{m}$ & $\mathrm{m}$ & \\
\hline$\gamma_{\text {dry }}$ & 16 & 12 & 17 & 14 & 16.5 & 16.25 & 15 & $\mathrm{kN} / \mathrm{m}^{3}$ \\
$\gamma_{\text {sat }}$ & 19 & 18 & 20.4 & 19 & 19.5 & 20 & 19 & $\mathrm{kN} / \mathrm{m}^{3}$ \\
$\mathrm{E}_{\text {SLS }}$ & 4 & 3 & 22 & 8 & 40 & 24 & 79 & $\mathrm{Mpa}$ \\
$v$ & 0.35 & 0.35 & 0.35 & 0.35 & 0.35 & 0.35 & 0.3 & - \\
$\mathrm{C}_{\text {ref }}$ & 40.89 & 12.1 & 36.55 & 22.68 & 45.76 & 28.77 & 19.4 & $\mathrm{kN} / \mathrm{m}^{2}$ \\
$\phi$ & 4.65 & 3.2 & 7.73 & 5.74 & 10.5 & 15.4 & 28.15 & $\circ$ \\
\hline
\end{tabular}

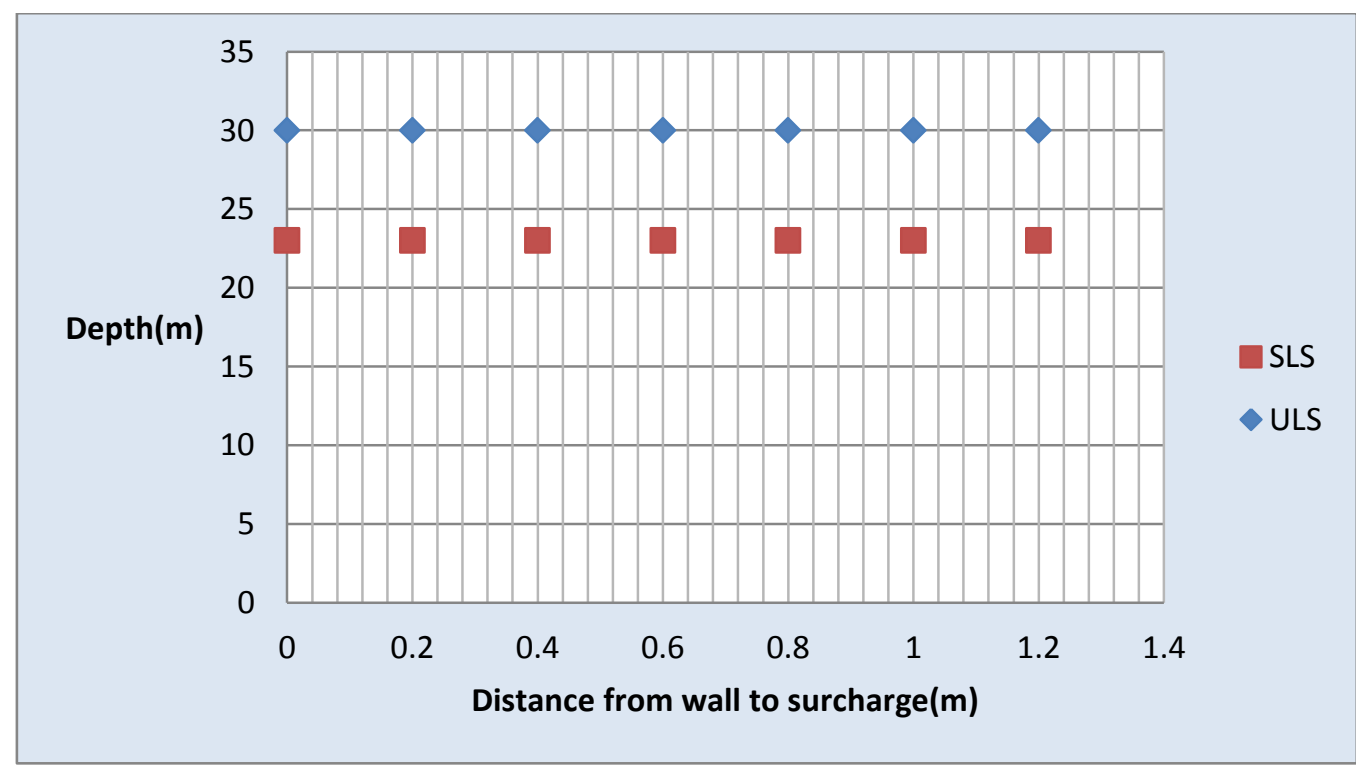

Figure 2. Wall depth with distance from wall to surcharge 
D. CASE D $2.5 \%$ Increasing shear strength parameter

1. In ULS, $17 \mathrm{~m}$ wall depth is needed for all distances from wall to surcharge. SUM Msf 1.927 at zero $\mathrm{m}$ distance from wall to surcharge and Maximum SUM Msf is 1.942 at $1.0 \mathrm{~m}$ distances from wall to surcharge. Minimum SUM Msf is 1.895 at $0.6 \mathrm{~m}$ distances from wall to surcharge.

2. In SLS, $17 \mathrm{~m}$ wall depth is required for all distances from wall to surcharge. Horizontal ground movement is $35.58 \mathrm{~mm}$ at zero $\mathrm{m}$ distance from wall to surcharge and Minimum horizontal displacement is $33.53 \mathrm{~mm}$ at $1.2 \mathrm{~m}$ distance from wall to surcharge. Wall deflections are same to horizontal displacement.
Maximum horizontal displacement is $35.7 \mathrm{~mm}$ at $0.6 \mathrm{~m}$ distance from wall to surcharge.

3. Vertical ground movement is 65.34 to 65.46 $\mathrm{mm}$ for all distances from wall to surcharge.

E. CASE E $3.0 \%$ Increasing shear strength parameter

1. In ULS, $17 \mathrm{~m}$ wall depth is needed for all distances from wall to surcharge. SUM Msf 2.315 at zero $\mathrm{m}$ distance from wall to surcharge and Maximum SUM Msf is 2.323 at $1.0 \mathrm{~m}$ distances from wall to surcharge. Minimum SUM Msf is 2.299 at $0.6 \mathrm{~m}$ distances from wall to surcharge.

2. In SLS, $17 \mathrm{~m}$ wall depth is required for all distances from wall to surcharge. Horizontal ground movement is $33.04 \mathrm{~mm}$ at zero $\mathrm{m}$

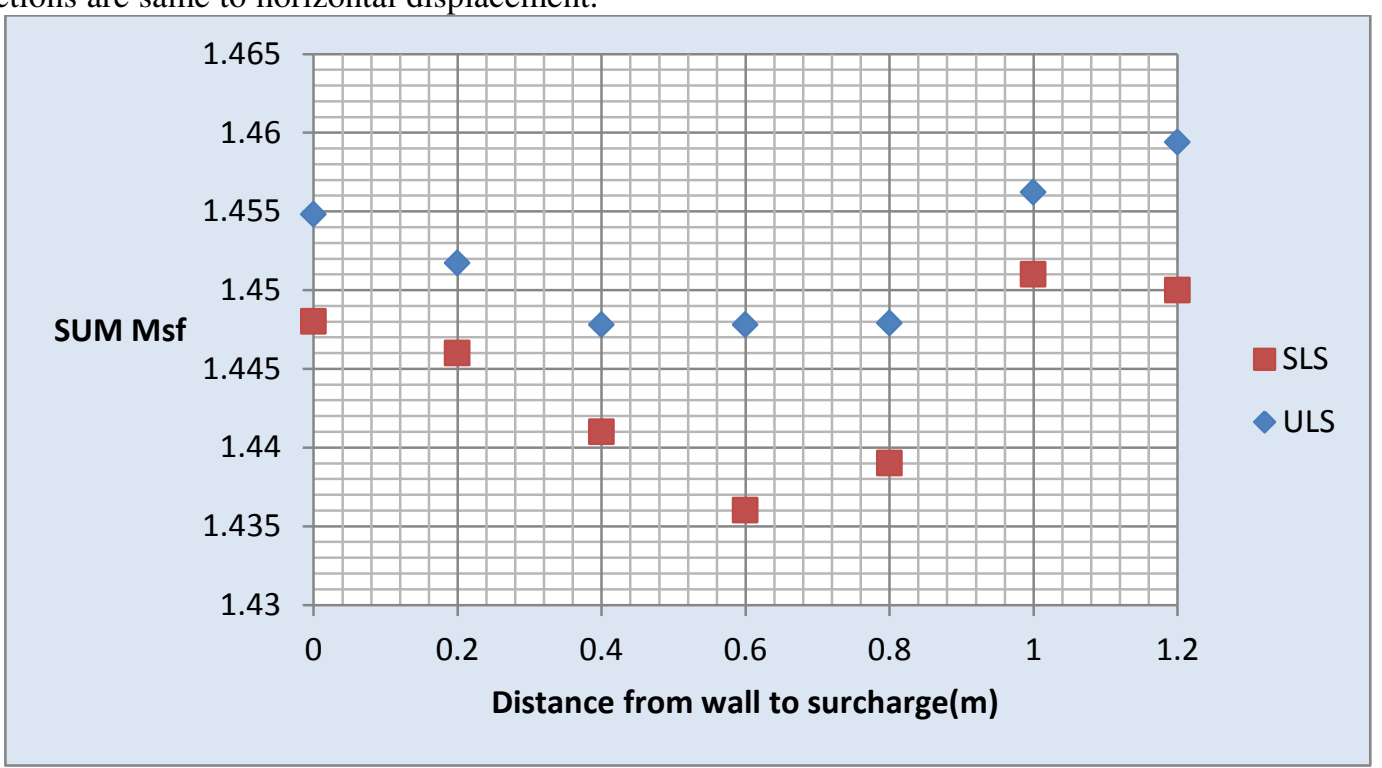

Figure 2 A. SUM Msf with distance from wall to surcharge

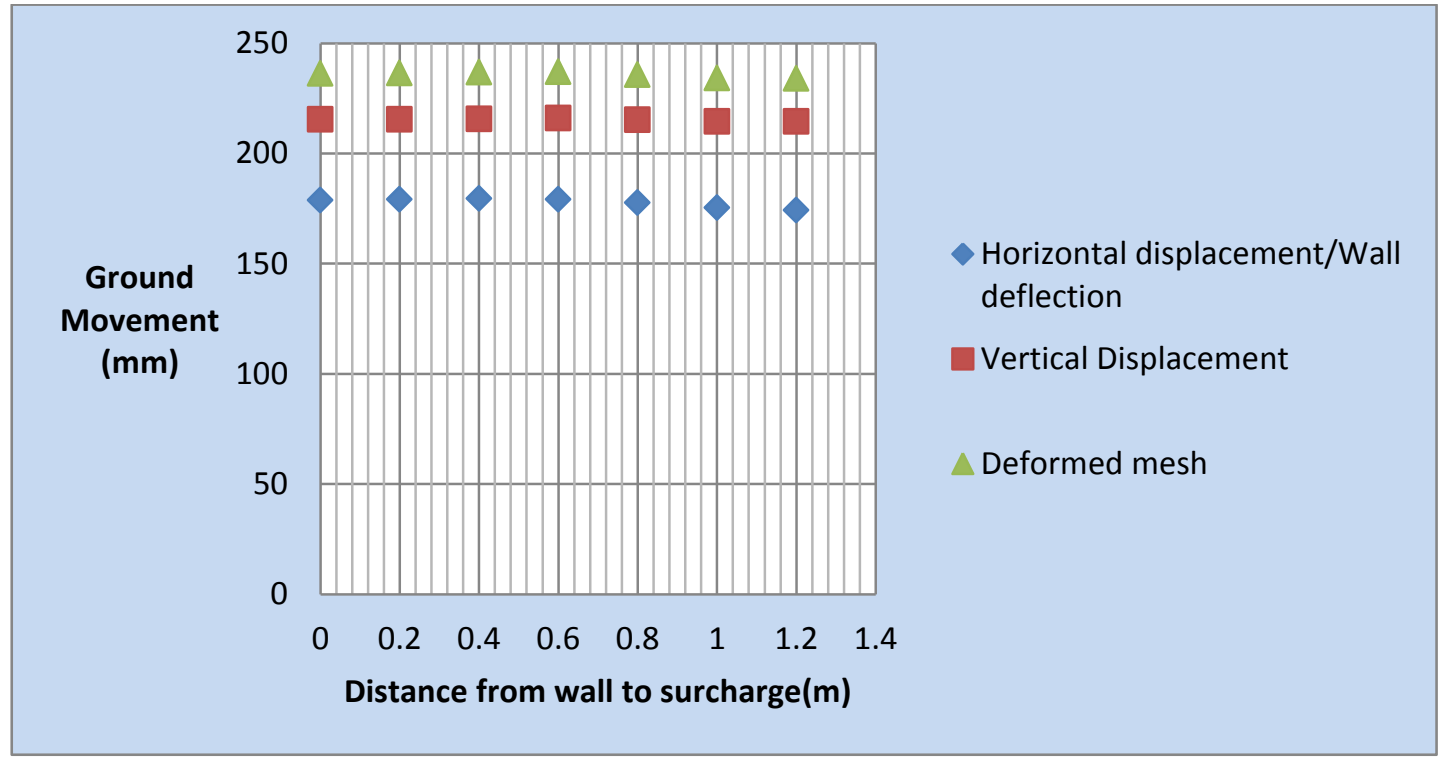

Figure 3. Ground movement with distance from wall to surcharge

distance from wall to surcharge and Minimum horizontal displacement is $32.69 \mathrm{~mm}$ at $1.2 \mathrm{~m}$ distance from wall to surcharge. Wall deflections are same to horizontal displacement. 
Maximum horizontal displacement is $34.8 \mathrm{~mm}$ at $0.8 \mathrm{~m}$ distance from wall to surcharge.

3. Vertical ground movement is $61.68 \mathrm{~mm}$ at zero $\mathrm{m}$ distance from wall to surcharge and that is minimum vertical displacement. Maximum vertical displacement is $62.03 \mathrm{~mm}$ at $1.2 \mathrm{~m}$ distance from wall to surcharge

F. CASE F $3.5 \%$ Increasing shear strength parameter

1. In ULS, $17 \mathrm{~m}$ wall depth is needed for all distances from wall to surcharge. SUM Msf 2.712 at zero $m$ distance from wall to surcharge and Maximum SUM Msf is 2.714 at $1.0 \mathrm{~m}$ distances from wall to surcharge. Minimum SUM Msf is 2.65 at $1.2 \mathrm{~m}$ distances from wall to surcharge.

2. In SLS, $17 \mathrm{~m}$ wall depth is required for all distances from wall to surcharge. Horizontal ground movement is $22.26 \mathrm{~mm}$ at zero $\mathrm{m}$ distance from wall to surcharge and Minimum horizontal displacement is $22.11 \mathrm{~mm}$ at $1.0 \mathrm{~m}$ distance from wall to surcharge. Wall deflections are same to horizontal displacement. Maximum horizontal displacement is $22.36 \mathrm{~mm}$ at $0.6 \mathrm{~m}$ distance from wall to surcharge.

3. Vertical ground movement is 46.96 to $47.07 \mathrm{~mm}$ for all distances from wall to surcharge.

G. CASE G $4.0 \%$ Increasing shear strength parameter

1. In ULS, $17 \mathrm{~m}$ wall depth is needed for all distances from wall to surcharge. SUM Msf 3.06 to 3.09 for all distance from wall to surcharge.

2. In SLS, $17 \mathrm{~m}$ wall depth is required for all distances from wall to surcharge. Horizontal ground movement is 21.32 to $21.67 \mathrm{~mm}$ for all distance from wall to surcharge. Wall deflections are same to horizontal displacement.

3. Vertical ground movement is 45.7 to $45.8 \mathrm{~mm}$ for all distances from wall to surcharge.

H. CASE H $4.0 \%$ Increasing shear strength parameter

1. In ULS, $17 \mathrm{~m}$ wall depth is needed for all distances from wall to surcharge. SUM Msf 2.637 at zero $m$ distance from wall to surcharge and Maximum SUM Msf is 3.7 at $1.2 \mathrm{~m}$ distances from wall to surcharge. Minimum SUM Msf is 2.629 at $0.6 \mathrm{~m}$ distances from wall to surcharge.

2. In SLS, $17 \mathrm{~m}$ wall depth is required for all distances from wall to surcharge. Horizontal ground movement is $17.15 \mathrm{~mm}$ at zero $\mathrm{m}$ distance from wall to surcharge and Minimum horizontal displacement is $16.76 \mathrm{~mm}$ at $1.2 \mathrm{~m}$ distance from wall to surcharge. Wall deflections are same to horizontal displacement. Maximum horizontal displacement is $17.21 \mathrm{~mm}$ at $0.6 \mathrm{~m}$ distance from wall to surcharge.

3. Vertical ground movement is 41.72 to 41.81 $\mathrm{mm}$ for all distances from wall to surcharge.

I. Comparison of case study A to $\mathrm{H}$ at $\mathrm{Om}$ distance from wall to surcharge

1. Figure 8 and Figure 9 shows to see easily results for wall depth and ground movements due to increasing of shear strength parameter.

\section{J. Table 4 shows Increasing of shear strength parameter.}

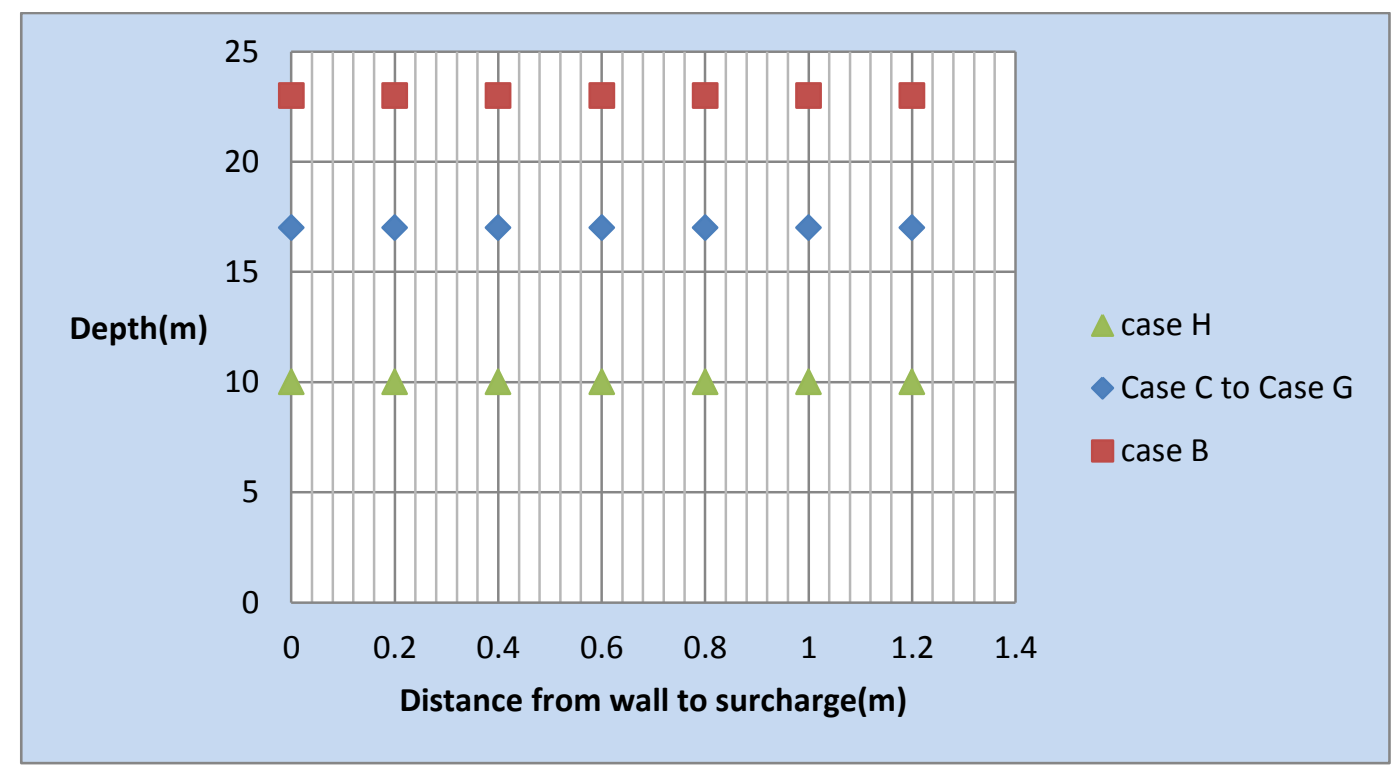

figure 4.Wall depth with distance from wall to surcharge(ULS) 
The Third International Conference on Civil Engineering Research (ICCER) August $1^{\text {st }}-2^{\text {nd }}$ 2017, Surabaya - Indonesia

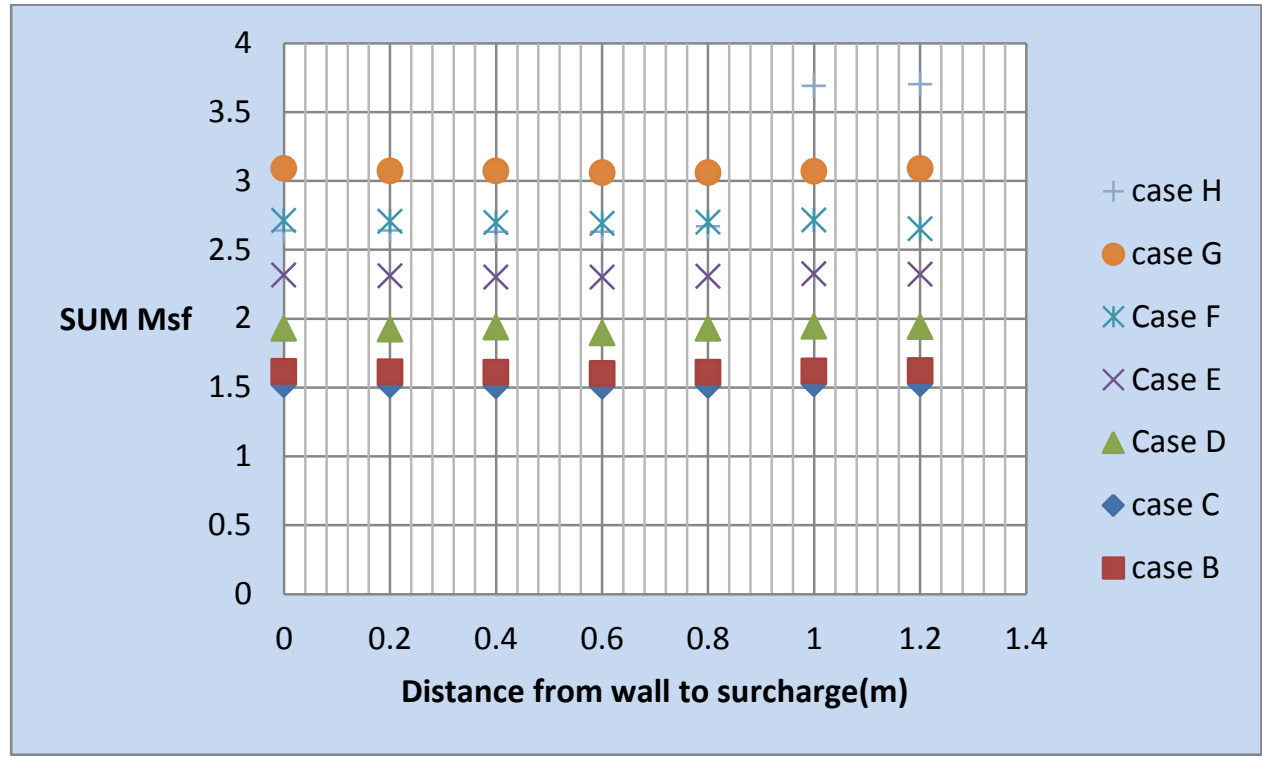

Figure 5.SUM Msf for wall depth(ULS) with distance from wall to surcharge

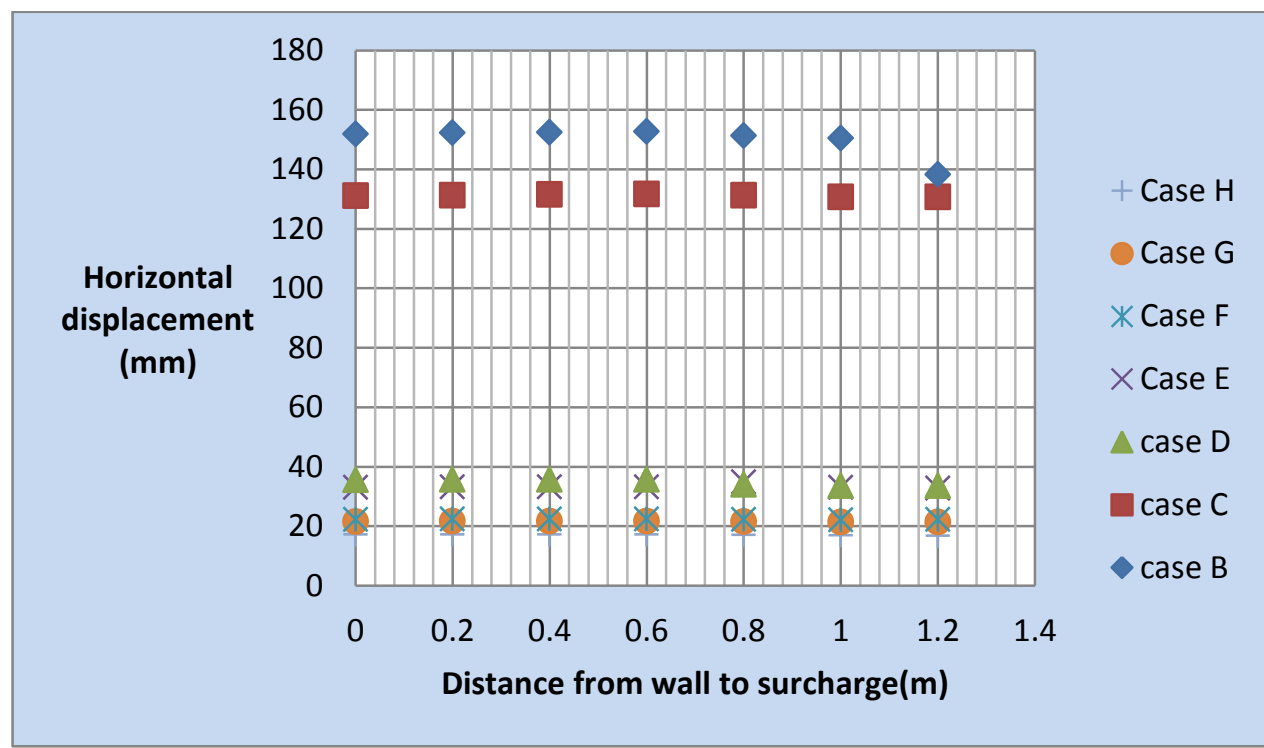

Figure 6.Horizontal displacement with distance from wall to surcharge

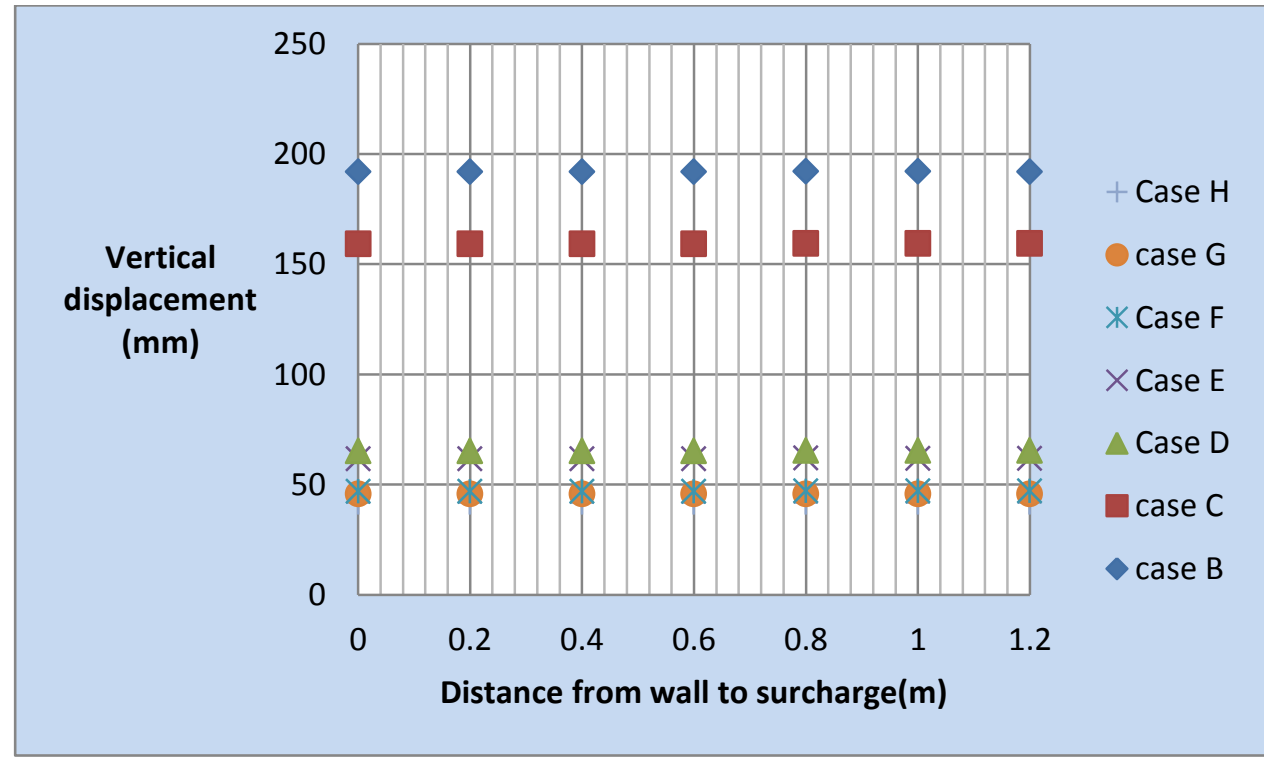

Figure 7.Horizontal displacement with distance from wall to surcharge 


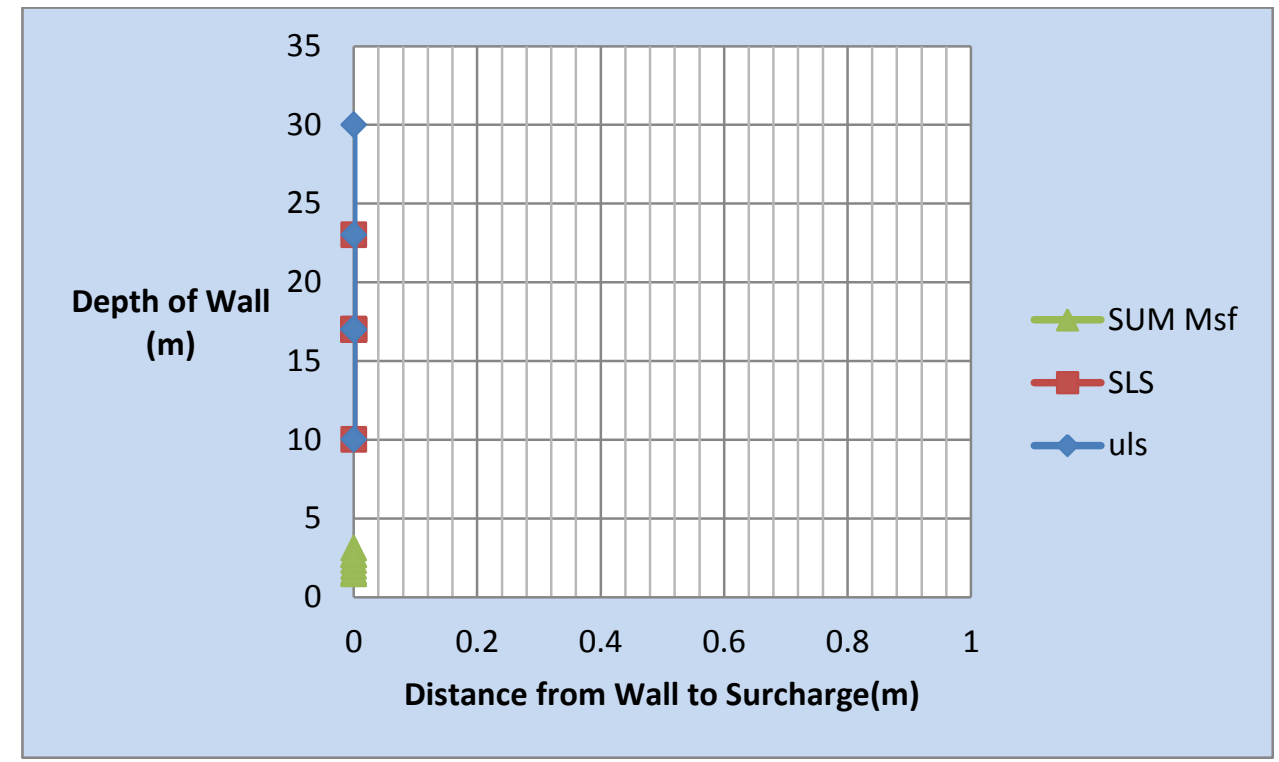

Figure 8 .Depth of Wall with increasing of shear strength parameter

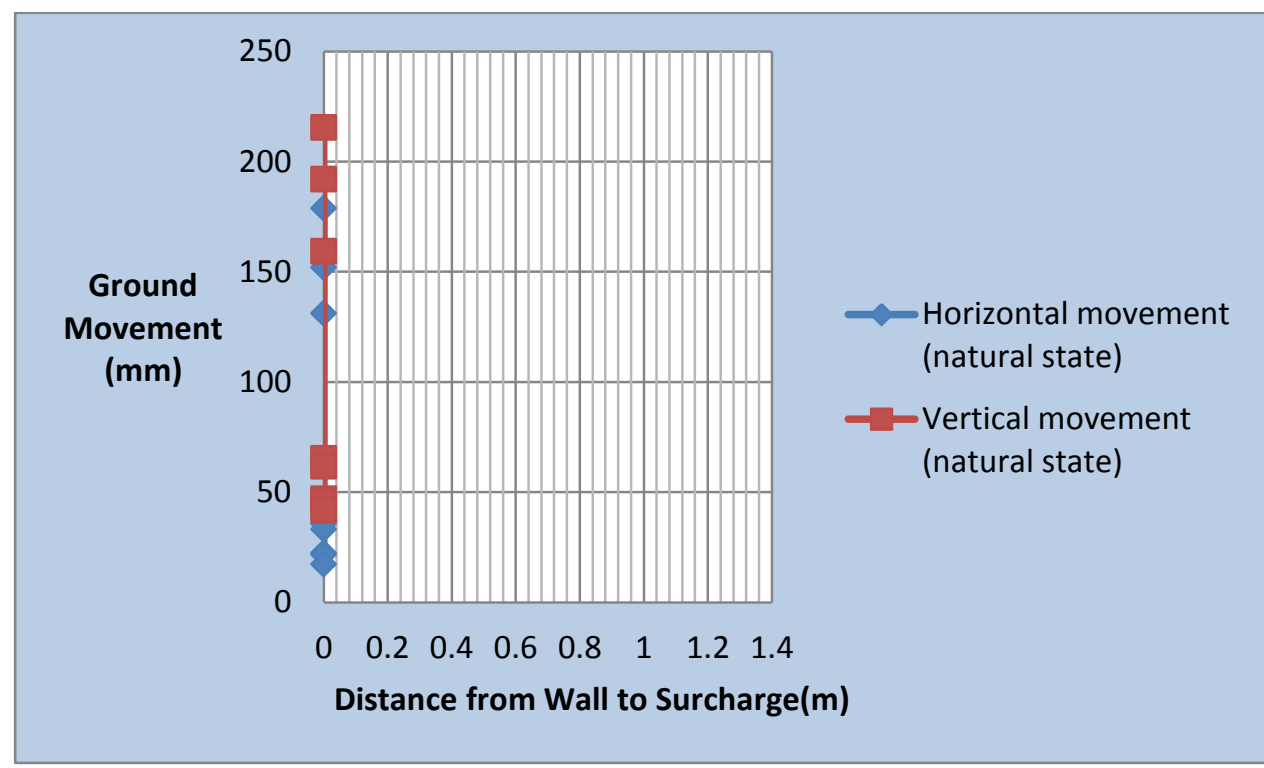

Figure 9.Ground movement with increasing of shear strength parameter

\section{CONCLUSION}

1. From the results, Surcharge load should be placed at zero distance from the wall or distance from wall to surcharge is more than $1.2 \mathrm{~m}$.

2. In Natural soil condition, ground movements are more than limitation amount because layer 1 is soft clay and layer 2 is medium (low) until $15 \mathrm{~m}$ depth from ground surface. Wall depth is not change from all distances from wall to surcharge.

3. In Increasing of shear strength parameter condition (case D to $\mathrm{H}$ ): Decreasing of Horizontal ground movements and Vertical ground movements are dominantly because changing of normally consolidated clay to over consolidated clay in layer 2 .

4. CASE $\mathrm{H} 4.5 \%$ Increasing shear strength Parameter: Soil condition of Layer 2 starts to change stiff state. Therefore below dredged level become stiff condition. Although it is not strong stiff, horizontal ground movements reach acceptable limit $(0.5 \%$ of $\mathrm{H})$. Wall depth becomes more economical and good working condition. Vertical movement is less than limit value of $1 \%$ of $\mathrm{H}$. But to be more satisfied limit $0.5 \%$ of $\mathrm{H}$, It is need to compact the dredged level with granular soil.

5. $5 \mathrm{~m}$ depth cantilever retaining wall is supported by embedment stiff clay to reach overall economy.

\section{ACKNOWLEDGEMENTS}

I wish to knowledge and thank all persons who kindly helped and supported me in every stage of this research. My special thanks are due to Professor Dr. Khin Than $\mathrm{Yu}$, Pro Rector, Yangon Technological University, Dr. Nyan Myint Kyaw, Professor, Department of Civil 
Engineering, Yangon Technological University for their and invaluable guidance during my study. kind permission of this study, approval of this research,

Table 4. Increasing of shear strength parameter for Case Study B to H

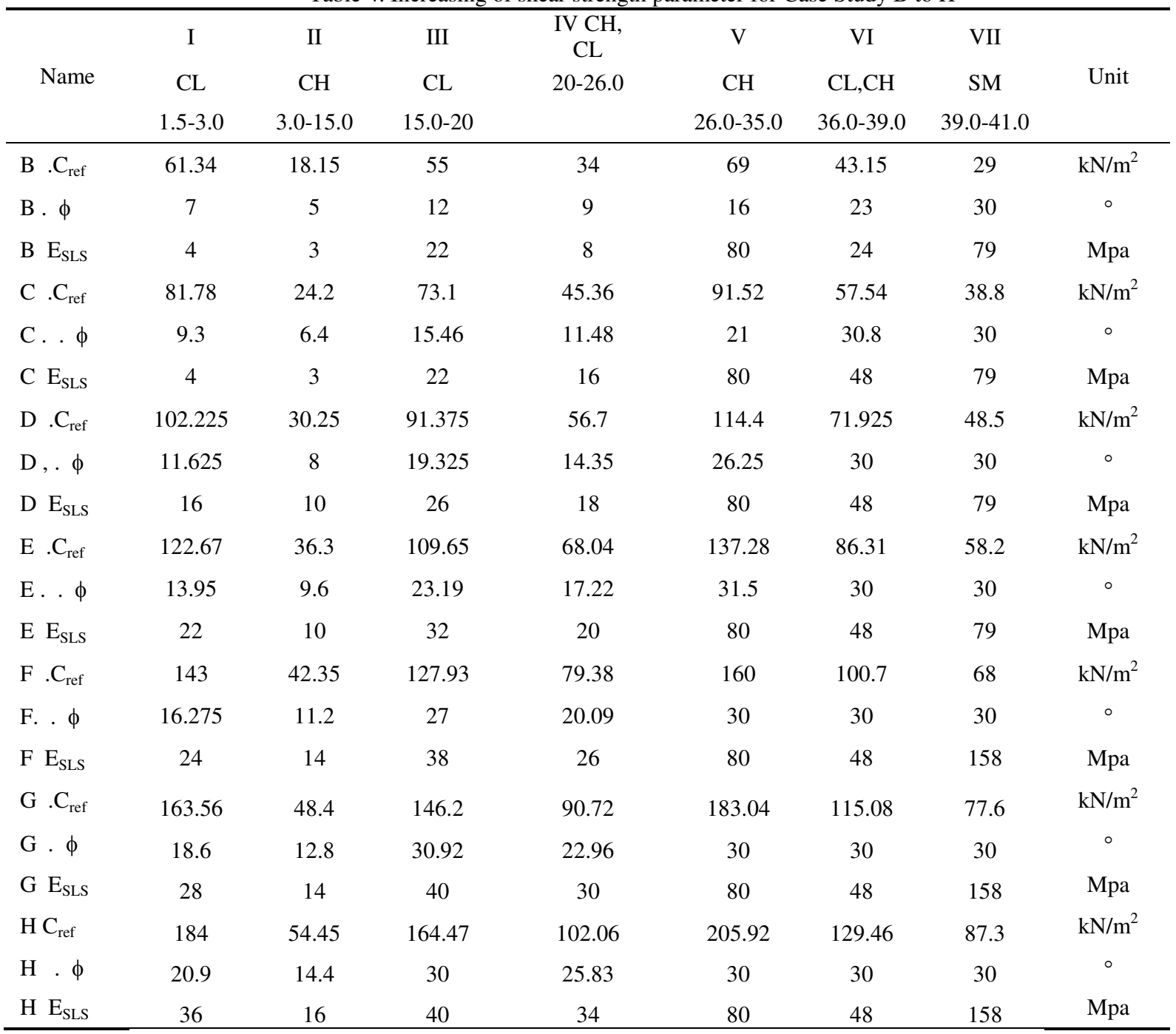

\section{REFERENCES}

[1] Asim Gaba, Brain Simpson, William Powrie., David Beadman, "Embedded Retaining Walls-Guidance for Economic Design” London. 2003. UK.

[2] "Code of practice for Earth Retaining Structures" BS 8002: 1994

[3] Braja M.Das. California State University, Sacramento. "Principles of Foundation Engineering" Seven Edition, United State of America. 2011

[4] Chang Yu Ou Department of construction Engineering, National Taiwan University of Science and Technology, "Deep Excavation Theory and Practice" 2006,taylor \& Francis Group, London,UK

[5] James K. Mitchell, Kenichi Soga. "Fundamentals of soil behavior "—-3rd ed, 2005

[6] R.F Craig. Department of Civil Engineering, University of Dundee. “Soil Mechanics", Six Edition, UK. 1990. 1990.
[7] Braja M.Das. California State University, Sacramento. "Principles of Geotechnical Engineering," Eight Edition, United State of America. 2014

[8] Shamsher Prakash, Professor of Civil Engineering, University of Missouri- Rolla, Harid.Sharma, Chief Geotechnical Engineer, Emcon Associates, San Jose, California. "Pile Foundations in Engineering Practice", United State of America. 1990.

[9] Joseph E.Bowles, P.E., S.E.._"Foundation Analysis and Design". Fifth Edition, United State of America. 1977

[10] LYMON C. REESE,WILLIAM M. ISENHOWER, SHINTOWER WANG "Analysis and design of deep foundations "2006 by John Wiley \& Sons, Inc.

[11] Braja M.Das. California State University, Sacramento. "Advanced Soil Mechanics", Second Edition, United State of America. 1997 